\title{
Gender verification in sport: the need for change?
}

\author{
M. A. Ferguson-Smith FRCPath, FRS ${ }^{1}$ and Elizabeth A. Ferris MB BS ${ }^{2}$ \\ ${ }^{1}$ Professor of Pathology, University of Cambridge \\ ${ }^{2}$ Medical Officer for the Modern Pentathlon Association of Great Britain
}

\begin{abstract}
Most of an estimated one in 504 sportswomen fail the gender verification test unjustly. Until clinical examination becomes acceptable, a new code of practice is proposed which avoids unfair disqualification.
\end{abstract}

Genetically determined sex differences in stature, musculature and cardiovascular capacity result in males having a substantial advantage over females in those sports which, in general, require strength, speed and power. It is well documented that differences in performance between highly trained men and women are considerably less than those that exist between average men and women ${ }^{1,2}$. This justifies the continued segregation of men and women in all but a few sports (e.g. equestrian events and shooting).

\section{Historical background}

Since males have the advantage, it is understandable that occasionally males might be tempted to masquerade as female athletes. In other cases, males who were born with ambiguous genitalia and raised as females have found themselves to be physically at an advantage over other sportswomen. Whilst cheating maybe rare, there is anecdotal evidence that individuals who have competed as females have subsequently changed their sexual identity to live as men. There are some well documented examples.

1. The Olympic $100 \mathrm{~m}$ women's sprint champion in 1932 was discovered to have testes at autopsy when she was a victim of a shooting incident in 1980. The coroner's report said, 'The problem is a subtle one which requires chromosome tests to settle once and for all the questions of her gender ${ }^{3}$.

2. The European women's high jump champion and world record holder in 1938 was barred from competition when she was found to have male and female sex organs and was said by the German Athletic Federation to have 'no right to participate in women's competitions ${ }^{\prime 4}$.

3. The winner of the women's $800 \mathrm{~m}$ and world record holder in 1934 later had a sex-change operation to become a $\operatorname{man}^{5}$.

Address for correspondence: Professor M. A. Ferguson-Smith, Cambridge University Department of Pathology, Tennis Court Road, Cambridge CB2 1QP, UK

Based on a contribution to the British Olympic Association Medical Conference, November 1989

(C) 1991 Butterworth-Heinemann Ltd.

0306-3674/91/010017-04
4. Two members of a women's relay team which was second in the European Championships in 1946 subsequently underwent sex changes, and one became a father ${ }^{4}$.

5. One runner broke world track records in 1964 at 400 and $800 \mathrm{~m}$ that were never ratified, and she was later discovered to be male ${ }^{6}$.

6. The winner of the women's world downhill ski title in 1966 retired after taking a medical examination in 1967, and after surgery was pronounced a male; he married and became a father ${ }^{6}$.

It is likely that in most of these cases there was some abiguity of the external genitalia and testicular maldescent and their androgen levels may have contributed to their success. These cases, together with rumours and innuendo generated at the Rome Olympics in 1960, prompted the International Amateur Athletic Federation (IAAF) and subsequently the International Olympic Committee (IOC) to consider establishing rules of eligibility for women athletes to ensure that 'the athletes are competing on an equal basis, considering their physical status' 7 . At the same time there was also growing concern about the possible use of drugs by athletes, and this clearly had an influence on the decision to attempt to stop all forms of cheating.

Recognition of the problem as early as 1948 had led the British Women's Amateur Athletic Association, to require a doctor's letter verifying the sex of women competitors. This was considered later to be too open to abuse to be effective against a determined imposter, and so in 1966, at the European Athletics Championships in Budapest, women athletes were required to undergo an inspection before a panel of three women doctors ${ }^{8}$. The 243 athletes who were all pronounced normal, understandably found this procedure demeaning. Unexpectedly, five world record holders did not attend.

At the Commonwealth Games in Kingston, Jamaica in 1966 a physical examination was again required. This time a manual examination of the external genitalia was performed by a gynaecologist ${ }^{9}$. Naturally, the athletes deeply resented this treatment and similar indignation was expressed at the Pan American Games in Winnipeg, Canada in 1967 when an 'on sight' inspection was carried out ${ }^{8}$. Widespread resentment of these insensitive forms of examination prompted the IOC to consider other methods of testing for femininity; and the sex chromatin test was proposed as a more acceptable means of assessing eligibility and preventing cheating ${ }^{10}$. 


\section{Paradoxical findings between anatomical sex and the sex chromatin test}

The sex chromatin test, also known as the buccal smear test, consists of a microscopic examination of epithelial cells scraped from the inside of the cheek. The cells are stained to reveal the presence or absence of the Barr body, which is caused by inactivation of one of the two $\mathrm{X}$ chromosomes in female cells and which appears in $20-30 \%$ of nuclei. Male cells do not show this Barr body as they have only one active $X$ chromosome. The test therefore indicates the number of $\mathrm{X}$ chromosomes in the cell nucleus and thus reflects the sex chromosome constitution of the individual, normally $\mathrm{XX}$ in females and $\mathrm{XY}$ in males.

Normally a person's anatomical sex (and thus social and legal sex) is determined by the type of sex chromosome contributed by the father. However, there are a number of genetic disorders which interfere with the process of sex development and lead to paradoxical findings between anatomical sex and chromosomal sex. Thus some individuals with an apparently normal male chromosome constitution develop to adulthood as girls. These individuals are referred to as $X Y$ females. They are recognized after puberty because they fail to menstruate and remain infertile; the breasts may fail to form and the vulva and vagina do not mature. Many, however, grow into normal-looking women and, as they are otherwise healthy and sometimes taller than average, they tend to do well in sport. The two most common conditions are gonadal dysgenesis, in which only vestiges of the gonads remain and no male hormones are produced, and androgen insensitivity (or testicular feminization syndrome), in which the uterus is not formed and intra-abdominal testes produce normal amounts of testosterone.

\section{Androgen insensitivity syndrome}

The cause of androgen insensitivity is due to failure of cells to respond to testosterone because they cannot form normal androgen receptors. Consequently, the secondary sex characteristics and musculature are female and pubic and axillary hair are sparse. The condition is due to a mutant gene carried on the $\mathrm{X}$ chromosome.

The androgen insensitivity syndrome is the commonest abnormality detected by sex chromatin tests in sport, and is of most concern to those wishing to change the eligibility rules ${ }^{11,12}$. It is also the cause of most misunderstanding, for many people involved in sport do not understand why the presence of hormone-secreting testes in women with normal external genitalia (including vagina) and normal breast development, does not confer advantage over normal women in terms of muscle mass. This may be better understood when it is realized that those affected are not able to respond to anabolic steroids. Women with androgen insensitivity are also taller than average, although within the normal range. This appears to be due to genes for stature carried by the $Y$ chromosome. However, there is considerable variation in height amongst normal women due to genes carried by other chromosomes. Individuals with these forms of genetic variation are self-selected in certain sports, for example volleyball and high jump, and it would seem unfair to accept genetic variation for height of one origin and exclude another.

\section{Gonadal dysgeneses}

There are several genetic causes of gonadal dysgenesis: some cases lack male determinants due to mutations of the testis-determining region of the $Y$ chromosome, others may be due to $X$ chromosome mutations. Similar conditions in animals are known to be due to mutations of the non-sex chromosomes.

\section{Other chromosomal abnormalities}

In addition to $X Y$ females, there occur other genetic conditions in which the sex chromatin test gives a paradoxical result. Most are rare and there is little evidence as yet that they cause difficulty with regard to eligibility in sport. This may be because the sex chromatin test would reveal a Barr body, and the affected person would escape detection.

In one group, referred to as $X X$ males part of the $Y$ chromosome containing the testis determinants has been transferred to one of the two $\mathrm{X}$ chromsosomes. The Barr body test is positive, but the individual usually develops as a normal-appearing male. Height is within the normal female range, breast development is common and, in a few cases, the genitalia are ambiguous $^{13}$.

More common are a group of infertile males with Klinefelter's syndrome who have an XXY sex chromosomal complement. Variants of this condition occur in whom a proportion of the body cells have normal $X X$ or $X Y$ sex chromosome complements - a condition referred to as mosaicism. Those mosaics who have normal female cells in addition to XXY cells, may be women with ambiguity of the external genitalia.

It seems likely that one of the best known female athletes to be excluded from international events on the grounds of ineligibility had XX/XXY mosaicism. She won gold and bronze medals at the Tokyo Olympics in 1964 and held the world record for the women's $100 \mathrm{~m}$. In 1966 she passed the inspection at the European Championships in Budapest but the following year in Kiev she was ruled ineligible for the European Cup women's track and field competition, having failed the eligibility test that involved a close-up inspection of the external genitalia. A six-man medical commission investigated her case, and chromosome analysis showed that she had an $X X Y$ sex chromosome complement ${ }^{8}$. It is understood that testes had been surgically removed at an earlier stage and that she was being treated with oestrogens. The irony is that had she been tested 1 year later at the Mexico Olympics she would have been eligible on the grounds that she was Barr body positive. Instead, she was disqualified from competing in women's athletics and in 1970 the International Amateur Athletic Federation removed her name from the record books.

This is the only case since gender verification was introduced in which a woman athlete has had to 
Table 1. Gender verification in sport: some results of sex chromatin testing

\begin{tabular}{lrlrc}
\hline Site & Year & \multicolumn{1}{c}{ Event } & $\begin{array}{c}\text { No. } \\
\text { tested }\end{array}$ & $\begin{array}{c}\text { No. } \\
\text { ineligible }\end{array}$ \\
\hline Munich & 1972 & Olympic Games & 1280 & 3 \\
Montreal & 1976 & Olympic Games & 1800 & 0 \\
Glasgow & 1978 & IAAF Cross-country & 49 & 0 \\
Los Angeles & 1984 & Olympic Games & 2500 & 6 \\
Kobe & 1985 & Universiade & 523 & 3 \\
Glasgow & 1987 & 7th World Netball & 186 & 1 \\
Auckland & 1990 & Cournament & & 0 \\
Total & & & 6561 & 13 \\
& & & & $(1$ in 504) \\
\hline
\end{tabular}

IAAF, International Amateur Athletics Federation

suffer public disgrace as a result of anomalous sexual differentiation. Since then, international sports organizations have taken great pains to maintain absolute secrecy. While it is essential to maintain confidentiality about individual cases, the secrecy surrounding testing has led unnecessarily to difficulty in determining the proportion of athletes who 'fail' the sex chromatin test (Table 1) and in obtaining data about the diagnoses of those who have their sexual status investigated.

\section{Male intersex}

The Medical Commission of the International Olympic Committee is also concerned about those with more complex genetic abnormalities and who may have an unfair advantage if they compete in women's events. These are male intersexes (or pseudohermaphrodites) who have varying degrees of testicular development but who respond at least partially to androgens secreted by the testes. They tend to have ambiguity of the external genitalia and masculinize at puberty. Owing to inadequate development of the penis, many are raised as females, but some undergo sex-change operations in late adolescence. The Commission believe that there have been cases where such individuals have been selected for training as women athletes and have thus been deprived of proper treatment. Although, there is no documentation which we can find to support this claim, it is possible that some of the examples quoted above before eligibility testing may fall into this category of male intersex. They are invariably infertile and this diagnosis is excluded in those later fathering children.

\section{Trans-sexualism}

The male trans-sexual is a normally developed male who undergoes a sex-change operation with removal of testes and genitalia and construction of an artificial vagina. Oestrogens enable them to appear and live as women. In 1976, a player who had previously undergone a sex change operation was allowed to enter the US Open Tennis Tournaments in 1976 after a Supreme Court Justice ruled that there was overwhelming medical evidence that this individual 'is now a female ${ }^{\prime 14}$. She therefore gained this right in law even though she would have failed the sex chromatin test which has become mandatory for all other women players who wish to enter US Tennis Association tournaments. We think that trans-sexuals should be excluded from international athletic events, if only because of the remote possibility that young male athletes may be persuaded to undergo sex-change operations.

\section{Other genetic disorders}

Other genetic disorders might confer unfair advantage to women athletes. Androgen-secreting tumours may lead to hirsutism and increased muscle mass, but it is unlikely that such cases would excel in sport. However, it is conceivable that females with the metabolic defect 21-hydroxylase deficiency, which results in the production of excess androgenic hormones by the adrenal gland, may have an advantage in some sports. The most severe forms of this condition (congenital adrenal hyperplasia) result in virilization before birth in females and precocious puberty in boys. Milder forms occur in healthy ${ }^{15}$ but infertile women. They are muscular, have a male body build and are often hirsute. Diagnosis is by examination of urinary hormone levels after adrenocorticotrophic hormone stimulation. As genetic females, they pass the sex chromatin test. However, the condition has not yet been identified in athletes. Affected males might benefit in sport from the additional androgen production of their adrenals, but information on this is also lacking. It is questionable whether or not the metabolic 'advantage' conferred by 21-hydroxylase deficiency should render female competitors ineligible. It could be argued that, as it is another example of natural genetic variation, it should not be grounds for disqualification.

\section{Results of eligibility testing in sport}

The sex chromatin test is more likely to exclude athletes unfairly than to detect those who cheat. Although it is not the intention of the Medical Commission of the IOC to exclude cases of androgen sensitivity, the effect of eligibility tests is that almost all such cases are excluded. This is because the affected athlete, having failed the chromatin screening test, prefers to retire immediately without submitting to chromosome analysis, blood hormone tests and gynaecological examination the results of which could lead to an eligibility certificate being issued. This may indicate a lack of proper counselling and uncertainty about the correct procedure to follow. At the Munich Olympics in 1972, sex chromatin tests were performed on hair roots instead of buccal smears. Y chromatin (detected by fluorescence staining) was added to the Barr body test and three of the 1280 athletes tested were found to be ineligible for reasons which are unknown ${ }^{16}$. It seems that cheating, for which the sex test was introduced 
in the first place, may not have been prevented by using these tests for it was alleged that one of the Asian women's volleyball teams at Munich included a man ${ }^{8}$. At the 1976 Montreal Olympics, 1800 tests were performed (all normal). At the Universiade Games in Japan in 1985 the results were published ${ }^{17}$. Three of 523 female athletes were excluded, two were $X Y$ females with androgen insensitivity and the other was a complex mosaic with both $X$ and $Y$ chromatin. One with androgen insensitivity 'passed' the sex chromatin test at the World Championships in Helsinki 2 years previously and has since been granted an eligibility certificate on appeal, but only after much distress. The information that we have managed to gather about the frequency of $X Y$ females and other ineligible athletes suggests a figure of 1 in 500-600 sportswomen (Table 1). We know of no case in which the sex chromatin test has exposed a man masquerading as a woman.

Concerning unsatisfactory eligibility tests, $\mathrm{Dr}$ Eduardo Hay wrote in 1981 on behalf of the IOC Medical Commission to one of us (E.A.F.) that he knew of at least 12 cases in which a woman athlete had been excluded by a sex chromatin test without either chromosome analysis or gynaecological examination. We know of two additional athletes with androgen insensitivity, tested in their own country and disqualified from future competition. Another athlete was barred from an important international event because of an erroneous $Y$ chromatin test; the sex chromatin test was done 3 months later and found to be normal. $Y$ chromatin testing is known to be unreliable and is no longer used.

Some genetic and endocrine societies have supported the movement to stop sex chromatin testing ${ }^{18}$. This has been resisted by the IOC Medical Commission on the grounds that the tests have succeeded in removing scandal and innuendo from international sport. What does not seem to be appreciated is the plight of those young female athletes erroneously excluded from competitive sport. Some opposed to sex chromatin testing for these reasons have suggested that a simple clinical examination should be used instead ${ }^{11,12}$. However, many athletes believe that sex chromatin testing protects them against cheating and would not wish it to be replaced by any form of physical examination which they regard as an invasion of privacy.

\section{Proposal for a new international code of practice for eligibility certification}

In order to reduce the possibility of error and allow time for correct interpretation of unexpected results, we propose the following:

1. The appropriate national association should be responsible for issuing eligibility certificates.

2. The certificates should be obtained at least 1 month (and preferably much earlier) before entering for an event.

3. Sex chromatin testing should be undertaken only by persons and laboratories accredited by the National Olympic Association and the international governing bodies of sport. Such persons should fully understand the limitations of testing and the significance of paradoxical findings. A named clinician with special expertise in disorders of sexual differentiation should be available for consultation. Genetic laboratories undertaking this work should demonstrate satisfactory quality assurance, at a level equivalent to that currently required of dope testing laboratories. Countries without appropriate testing facilities should have access to the nearest accredited laboratory.

4. The accredited laboratory should keep confidential records of all tests undertaken.

5. A sufficient number of spot checks of sex chromatin should be undertaken at the time of the competition to discourage falsification of documents. For example, finalists could be checked after the finals and at the same time as dope testing takes place. Competitors who are aware that they will fail such spot checks should be able to present detailed documentation of their eligibility at this time.

6. The purpose of eligibility testing is to exclude males from competing in women's events. It should be clearly understood that paradoxical findings may occur in women eligible to compete, for example in those with the androgen insensitivity syndrome and those with gonadal dysgenesis.

\section{References}

1 Wilmore JH. The application of science to sport: physiological profiles of male and female athletes. Can J Appl Physiol 1979; 27: 25-31.

2 Dyer KF. The trend of the male-female performance differential in athletics, swimming and cycling 1948-1976. J Biosoc Sci 1977; 9: 325-38.

3 Athletes's sex secret. The Guardian 1981; 26 Jan.

4 Donohoe T, Johnson N. Drugs and the female athlete, In: Foul play. Oxford: Basil Blackwell, 1986; 66-79.

5 Tachezy R. Pseudohermaphroditism and physical efficiency. $J$ Sports Med Phys Fitness 1969; 9: 119-22.

6 Ryan AJ. Sex and the singles player. Physician and Sports Med 1976; 4: 39-41.

7 Hay E. Sex determination in putative female athletes. JAMA 1972; 221: 998-9.

8 Larned D. The feminity test: a woman's first Olympic hurdle. Womensports 1976; 3: 8-11, 41.

9 Turnbull A. Women enough for the Games? New Scientist 1988; 15 Sept: $61-4$.

10 Editorial. Introducing the, uh, ladies. JAMA 1966; 198: 191-2.

11 de la Chapelle $\mathrm{A}$. The use and misuse of sex chromatin screening for 'gender identification' of female athletes. JAMA 1986; 256: 1920-3.

12 Simpson JL. Gender testing in the Olympics. JAMA 1986; 256: 1938.

13 Ferguson-Smith MA, Cooke A, Affara NA, Boyd E, Tolmie JL. Genotype-phenotype correlations in XX males and their bearing on current theories of sex determination. Hum Gent 1990; 84: 198-202.

14 Caldwell F. Victorious in court, she's defeated on court. Physician and Sportsmed 1977; 5: 26, 28.

15 New M, Levine LS. Recent advances in 21-hydroxylase deficiency. Ann Rev Med 1984; 35: 649-63.

16 Schwinger E. Problems of sex differentiation in athletics. Atleticastudi 1981; 5: 72-80.

17 Sakamoto $H$, Nakanoin $K$, Komatsu $H$, Michimoto $T$ Takashima E, Furuyama J. Femininity control at the XXth Universiade in Kobe, Japan. Int J Sports Med 1988; 9: 193-5.

18 de la Chapelle A, Genel M. Gender verification of female athletes. Lancet 1987; ii: 1265-6. 